\title{
Grounding the Human Body during Yoga Exercise with a Grounded Yoga Mat Reduces Blood Viscosity
}

\author{
Richard Brown ${ }^{1}$, Gaétan Chevalier ${ }^{2 *}$ \\ ${ }^{1}$ Human Physiology Department, University of Oregon, Eugene, USA \\ ${ }^{2}$ Developmental and Cell Biology Department, University of California at Irvine, Irvine, USA \\ Email:2rlbrownjr62@gmail.com, ${ }^{*}$ dlbogc@sbcglobal.net
}

Received 20 March 2015; accepted 5 April 2015; published 9 April 2015

Copyright (C) 2015 by authors and Scientific Research Publishing Inc.

This work is licensed under the Creative Commons Attribution International License (CC BY). http://creativecommons.org/licenses/by/4.0/

\section{(c) (i) Open Access}

\begin{abstract}
Objective: Research continues to show that being connected to the earth can increase the potential of the body to scavenge free radicals. This study examined the effect of just one hour of grounding on blood viscosity while subjects participated in gentle yoga exercises designed to initiate minor inflammation. Design: In this double blind model, twenty-eight (28) subjects met at the Bowerman Sports Medicine Clinic on the campus of the University of Oregon and were grounded to the earth via contact with a grounded yoga mat or were sham-grounded. Ten yoga exercises were repeated five times over a one-hour period. Blood was taken pre and post exercise and analyzed for blood viscosity using a scanning capillary viscometer. Results: Subjects connected to the earth significantly reduced their post exercise systolic blood viscosity $(p=0.03)$ and diastolic blood viscosity $(p=0.03)$. Conclusion: Grounding has the ability to affect exercise induced inflammation, thereby reducing blood viscosity.
\end{abstract}

\section{Keywords}

Earthing, Grounding, Yoga, Yoga Mats, Blood Viscosity

\section{Introduction}

\subsection{Earthing}

Earthing, also called grounding, consists in putting the human body in direct contact with the surface of the

${ }^{*}$ Corresponding author.

How to cite this paper: Brown, R. and Chevalier, G. (2015) Grounding the Human Body during Yoga Exercise with a Grounded Yoga Mat Reduces Blood Viscosity. Open Journal of Preventive Medicine, 5, 159-168.

http://dx.doi.org/10.4236/ojpm.2015.54019 
Earth. Examples: walking barefoot outdoors and bathing in lakes and oceans, or working, relaxing or sleeping indoors in direct skin contact with conductive materials. Such materials include bed sheets, pillows, body bands, mats and patches that are connected to the ground through a wire attached to a rod planted in the soil outside or using the grounding system (that is, the ground port of a grounded wall outlet) of a house or building. In industrial societies, most people today rarely come in contact with the surface of the Earth because they wear shoes with synthetic soles made from insulating materials (rubber and plastics). Also, they walk on carpets made of insulating materials and/or on wooden floors (wood is also an insulating material) and they sleep on mattresses that insulate them from the ground.

The Earth possesses an almost infinite reservoir of free electrons that is continuously replenished by a natural phenomenon called "the global atmospheric electrical circuit". [1] [2]. The Earthing hypothesis states the following: when contact is made with the ground by direct skin contact outdoors or through a grounded system indoors, the body's electric potential becomes the same as the Earth's electric potential, giving the body a continual access to the ground's negative surface charge mainly composed of electrons. It is well known that contact with the ground prevents buildup of static electric charge on the body [3], but what is less well known is that this contact enables the body to obtain as many electrons as needed for optimal functioning of physiological processes and to make a reserve of these antioxidant electrons for future use [4] [5].

According to current research, Earthing produces an array of positive changes within the body which include improved sleep, normalizing of cortisol levels, better glucose regulation, improved thyroid function, reduction in pain, decreased stress, increased blood fluidity, improved immune response, lessening of indicators of osteoporosis, and diminished damage to muscles caused by delayed onset muscle soreness (DOMS) [6]-[10].

Earthing has been found to decrease the duration of DOMS, one of only a very few strategies able to do so [7] [8] [11]. This Earthing effect significantly accelerates recovery time, a critically important benefit and advantage for all athletes with limited recovery time available. Examples are cyclists at the Tour de France who compete daily and football players who play weekly.

Along with muscle injury, exercise is known to produce inflammation in the body. Low levels of exercising may not produce much muscle damage, but still can increase inflammation in the body [12].

The present study was designed to see if the Earthing benefits would extend to people practicing a mild form of Hatha Yoga. It was hypothesized that a mild routine may not produce much muscle damage, but could produce an inflammatory response affecting blood viscosity. Inflammation produces an excess of reactive oxygen species (ROS) and reactive nitrogen species (RNS). These very reactive molecules are electronegative (attracting electrons) molecules. It is expected that the negative charge on the surface of red blood cells would be lowered during and after exercise, resulting in more viscous blood than normal [13] [14]. It is also hypothesized that being grounded during the Hatha Yoga routine would prevent this increase in inflammation and perhaps reduce the level of inflammation in the body.

\subsection{Blood Viscosity}

It has recently become appropriate to think of blood viscosity as a possible early warning sign of several chronic diseases, including cardiovascular disease and Alzheimer's [15]-[18].

Approximately 7.5 percent of body weight is blood (American Society of Hematology,

http://www.hematology.org/Patients/Basics/ accessed 2/26/2015). Red blood cells (RBC), white blood cells (WBC) and platelets make up most of the solid parts and represent about $45 \%$ of the blood volume. Plasma, the other $55 \%$, is a somewhat opaque, salty solution containing sugars, lipids, salt, vitamins, minerals, hormones, enzymes, antibodies, and proteins. Blood, via the pumping of the heart, delivers nourishment to, and removes waste from, all the body's cells.

Blood viscosity influences the ability of blood to flow through the arteries, veins and capillaries of the circulatory system. It is a measure of both thickness and stickiness of blood. Thickness and stickiness change as systolic and diastolic blood pressure change with each cardiac cycle [19]. Blood viscosity, a major determinant of blood vessel health, has been overlooked in the past due to difficulties in measuring viscosity at both systolic and diastolic blood pressure levels [19]-[22].

Factors affecting thickness and stickiness of blood are hematocrit, RBC/platelet aggregation, dehydration, low-density lipoprotein and fibrinogen [23]. Another factor is the ability of RBCs to deform and bend to more easily pass through capillaries [24]. The speed of the flow, partly a function of vessel diameter, also causes vis- 
cosity to change. The faster the blood flow, as in larger diameter vessels, the lower the viscosity. The slower the blood flow, as in smaller diameter vessels, the higher the viscosity [25].

Perhaps the most prevalent reason for increased blood viscosity in smaller vessels is red blood cell aggregation, due in part to inflammation and free radical activity causing reduction of negative surface electric charges (electrons) and electric potential. When the electric potential is reduced the cells have little or no negative charge and tend to clump [26].

Along with vessel diameter, blood viscosity affects the resistance to blood flow. If viscosity increases, total peripheral resistance increases and cardiac output, via increased systolic blood pressure, must increase. Therefore, viscosity is an important determinant of the work of the heart and of blood distribution [27].

The higher the viscosity of the blood is, the more its abrasiveness increases. In the large vessels, where blood velocity is fast, higher viscosity creates friction against vessel walls and may cause abrasions [27] [28], leading to inflammation and, ultimately, the development of plaque. Plaque reduces the diameter of the vessel contributing to further reduction of the vessel diameter and to clots that produce strokes [29] [30].

Plaque development occurs usually at locations of blood flow turbulence and eddies near the heart, neck and upper legs where vessels branch and blood viscosity is greater. At these points, hyperviscosity triggers endothelial dysfunction resulting in the hardening and thickening of arterial walls [30].

In the capillaries, where blood speed is slow and the diameter of vessels small, blood viscosity also causes problems. Red blood cells tend to lose some of the electric charge that keeps them separate and they tend to coagulate [26]. The older red blood cells also lose their ability to deform which creates a problem because without being able to bend through the capillaries, they cannot get to the cells. This decreases oxygen and nutrient delivery to the cells and eventually causes capillary damage [24].

\subsubsection{Blood Viscosity and Chronic Disease}

Higher blood viscosity is closely associated with many chronic diseases, including cardiovascular disease, diabetes, metabolic syndrome/obesity, and high blood pressure [15] [17] [18] [31]. It is also linked to cognitive decline, vascular dementia and Alzheimer's [32].

One study indicated that people with the highest blood viscosity had significantly higher cardiovascular events than people who had lower blood viscosity [33]. Another study found that the people with the highest blood viscosity had more than a four times risk increase of cardiovascular disease than people in the lowest group [34]. In a study of obese subjects it was determined that individuals with a body mass index over 28 had blood viscosities averaging $15 \%$ higher than those individuals with a lower body mass index [35].

\subsubsection{Physics of Blood Viscosity}

Blood viscosity depends on the ratio of shear stress to shear rate. Shear stress is the energy transferred to the vessel wall due to interaction with a fluid in motion. Shear rate is the variation of flow speed with radial distance from the center of the vessel [23] [36].

\section{Viscosity $=$ Shear Stress/Shear Rate}

Essentially, as shear rate decreases in the capillaries the ratio, and so the viscosity, increases significantly. As sheer rate increases, as in the larger vessels, blood viscosity decreases.

Water is a Newtonian fluid. The thickness and stickiness of water doesn't change. Blood is a non-Newtonian fluid in which blood thickness and stickiness change as the ratio changes. Until recently, most studies have presumed blood viscosity behaves as a Newtonian fluid. Very few studies have measured blood viscosity as a NonNewtonian fluid where adjacent layers move parallel to each other with different speeds [19].

Blood viscosity fluctuates with every heartbeat, just like blood pressure fluctuates with every heartbeat. And like blood pressure, accurate viscosity measurement requires two numbers [37]. You don't just measure systolic blood pressure because both systolic and diastolic pressures have meaning. The viscosity of the blood also depends on two numbers. One number, at systole, is when the viscosity is lower because it is thinner and the speed is faster. The other number is at diastole, when the viscosity is higher because it is thicker (more force required) and slower (less speed). Ideally whole blood viscosity should be measured at a physiologically comprehensive range of different shear rates. For the purpose of analysis, the results at two representative endpoints of shear rate, $5 \mathrm{~s}^{-1}$ and $300 \mathrm{~s}^{-1}$ have been studied and reported. The low-shear rate measurement of blood viscosity simulates bloodstream interaction during diastole, and the high-shear rate measurement simulates conditions at sys- 
tole. We use the term systolic blood viscosity to refer to high-shear viscosity and diastolic blood viscosity to refer to low-shear viscosity [37].

The systolic portion of blood viscosity is affected by hematocrit, plasma viscosity and hydration. It has a viscosity of around 30 millipoises $\left(\mathrm{mP}^{* * *}\right)$. The diastolic portion of blood viscosity is affected by immunoglobulins, red blood cell aggregation, platelet aggregation and fibrinogen. It has a viscosity of around 130 millipoises, and is much thicker and stickier. By comparison, water has a viscosity of about 10 millipoises [38]. When testing for viscosity it is important to test at both the systolic pressure and diastolic pressure [37].

\subsubsection{Blood Viscosity and Testing Equipment}

In the past, manual and rotational viscometers testing for blood viscosity limited observations to a single point measurement at systolic pressure (i.e., at high shear rates) when the blood is thinner and less sticky. They measured either serum or plasma viscosity and did not account for elements like red blood cell aggregation factors, red blood cell deformability or hematocrit [38].

Manual and rotational viscometers had several other disadvantages. The process was time consuming, technically demanding and depended upon the ability of the person doing the data interpretation. Standardization was almost impossible [37] [39].

This study used a state-of-the-art piece of equipment that eliminated all of the above problems. It is the Hemathix Blood Analyzer SCV-200, (Health Onvector Inc., Camden, NJ), an automated scanning capillary tube viscometer, invented by Dr. Young Cho, a fluid dynamics expert and professor of mechanical engineering at Drexel University. This instrument measures viscosity over a comprehensive range of shear rates representative of the cardiac cycle in a single continuous measurement.

Blood is collected by a venous puncture in a 3 milliliter lavender EDTA tube and is stable for 8 hours. If refrigerated, it is stable for 4 days. It cannot be frozen. Analyzing the data takes 4 minutes and results available the next day [40].

The Hemathix makes blood viscosity testing more practicable and affordable than in the past and enables standardization of viscosity screening. Eventually it has the potential to determine the viscosity profiles in the general population allowing early predictions of cardiovascular disease and other chronic diseases.

\subsubsection{Blood Viscosity Therapies}

Primary care physicians currently employ various strategies to lower blood viscosity, including diet and exercise, along with Omega 3 fish oils, are often suggested [41], as well as blood donation and therapeutic phlebotomy. Lipitor, Plavix, Coumadin and Fenofibrate reduce the blood viscosity by about the same amount as diet and exercise. However, these drugs have side effects that are at best unpleasant and at worst dangerous [37] [42]. Early studies suggest that Earthing (grounding) reduces blood viscosity [4] [5].

\subsubsection{Exercise and Blood Viscosity}

Earlier work has demonstrated the short and long-term effects of exercise on blood viscosity [43]-[45]. The short-term effect is an increase in blood viscosity [46], a function of duration and intensity of exercise, viability of the capillaries, red blood cell deformation characteristics, hematocrit and state of hydration. The long-term effect is a decrease in blood viscosity [46]. The goal of this study was to see if being grounded during a mild, short exercise of yoga would change blood viscosity, and in what direction.

\section{Material and Methods}

\subsection{Subjects}

Twenty-eight (28) healthy, non-pregnant women between the ages of 35 and 65, with a BMI between 25.1 and 31.4 and who completed a medical history form to ensure eligibility, participated in the study (Table 1). The Western Institutional Review Board (WIRB; www.wirb.com) provided supervision for the study. All subjects had to sign an informed consent agreement approved by WIRB. They were recruited in cooperation with yoga instructors of beginning yoga classes and had either just begun yoga instruction or wanted to begin. They were not experienced in yoga.

\footnotetext{
${ }^{* *}$ Poise-A unit of dynamic viscosity. $10 \mathrm{mP}=0.01$ gram/centimeter-second. In other words, $1 \mathrm{P}=1$ gram/centimeter-second. The metric unit of viscosity is the pascal second or Pa.s. $1 \mathrm{~Pa} \cdot \mathrm{s}=10 \mathrm{P}$ but poise or millipoise are more commonly used.
} 
Table 1. Age distribution of participants.

\begin{tabular}{cccc}
\hline & Sham Grounded & Grounded & t-Test Sham vs. Grounded \\
\hline No. of Subjects & 14 & 14 & 0.49 \\
Average Age & 49.1 & 49.0 & \\
SD & 6.4 & 7.7 & 0.37 \\
Average Height & 64.6 & 64.4 & 0.41 \\
SD & 1.9 & 2.6 & 0.22 \\
Average Weight & 159.6 & 160.6 & \\
SD & 14.8 & 9.1 & 27.3 \\
BMI & 26.8 & 1.7 & \\
SD & 1.7 &
\end{tabular}

Thirty-three (33) subjects were originally recruited. Two subjects did not produce enough blood to get satisfactory readings. Two other subjects had to leave because of impending surgeries. One was eliminated because when she was measured just before the study her BMI was too low.

\subsection{Study Procedure}

Prior to the study all subjects were provided with identical style shorts and tee shirts. They arrived one-by-one every ten (10) minutes. Each subject was met by a greeter and provided with a personal clipboard reviewing the instructions, timeline, and a bag in which to deposit outer garments and shoes. The subject then proceeded to a room for weighing, height measurement, and a single blood draw. Next, each participant proceeded to a designated meeting room where a personal yoga instructor reviewed the yoga instructions with the participant. Four instructors were utilized in the study, and gave the same instructions on how to do each pose. Fourteen (14) subjects were tested on Day 1 and fourteen (14) were tested on Day 2 between the hours of 10:00 AM and 12:30 PM.

Each subject selected a yoga mat at random. Seven (7) mats were grounded and seven were sham grounded. In this double blind study only the company providing the mats knew which mats were grounded, but they did not know which subjects used which mats.

Each subject participated in five (5) twelve (12) minute segments. Each segment was composed of the same group of ten (10) yoga poses (Figure 1). Each pose was held for one minute except for pose number 10. This pose was held for 2 minutes, followed by a one-minute rest period. The first 12 minutes of 10 poses on the mats was performed under the guidance of the instructor. During the next three segments the subjects repeated the poses with the instructor present. They then completed the last segment with no instructor present, but with one always available for guidance. Timing was consistent throughout these sessions with the use of coordinated timing lights of two different colors and a sound indicating when to change poses and segments.

After the last segment, participants reported back to the blood draw area for a post-exercise blood draw. They then retrieved their clothes and shoe bag, checked in with the greeter and turned in their clipboard with the timeline sheet initialed by monitors supervising each step of the procedure. They were then paid $\$ 60$, plus parking expenses and provided their address for the shipment of a complimentary grounded yoga mat. They kept their tee shirts and shorts.

\subsection{Blood Collection}

Blood was collected pre and post yoga mat exercise in a 3 milliliter lavender tube via a venous puncture by a certified phlebotomist from Legacy Labs in Eugene, Oregon. Legacy Labs labeled the blood tubes with subject numbers, then packaged and shipped them to Health Onvector Inc., a blood viscosity laboratory in Camden, New Jersey, in accordance with Hemathix instructions. The analysis results, via the Hemathix SCV-200 were available four days after receipt from the Camden lab. 


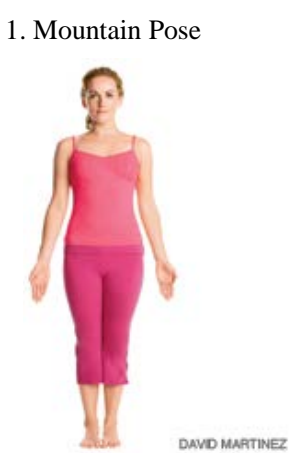

4. Warrior Pose Right

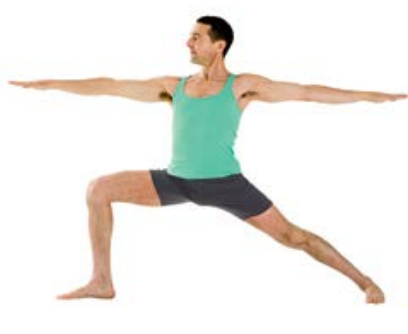

CHAIS NNDRE

7. Seated Twist Right

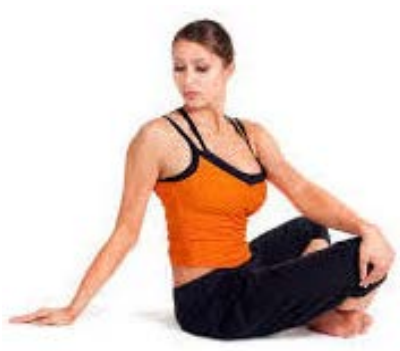

2. Upward Mountain Pose

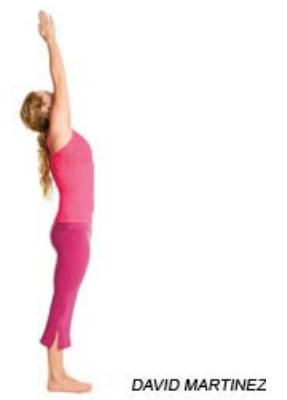

5. Warrior Pose Left

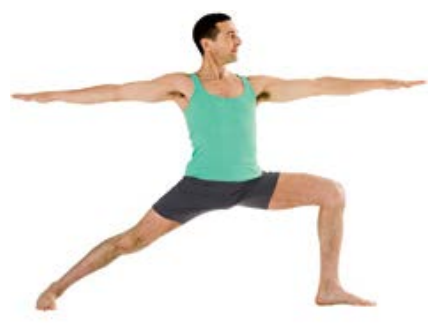

эноми ärно

8. Seated Twist Left

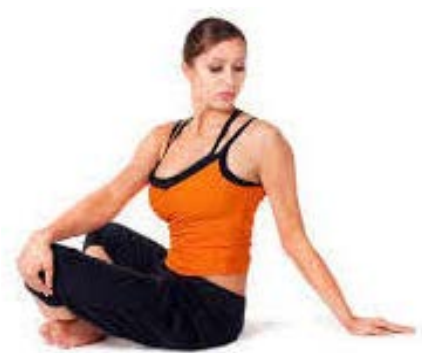

10. Two Footed Pose

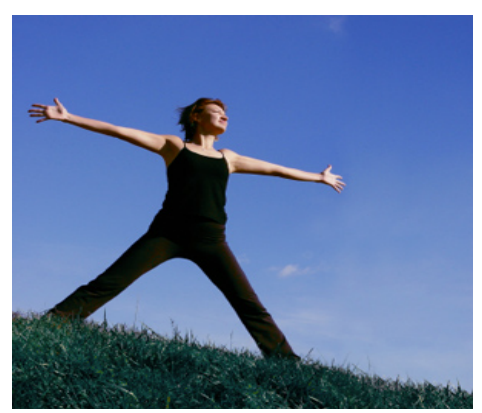

6. Wide Leg Seated

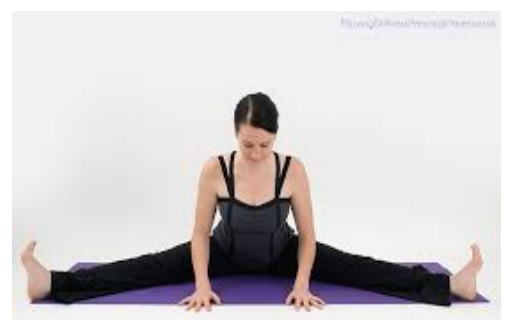

9. Knees to chest
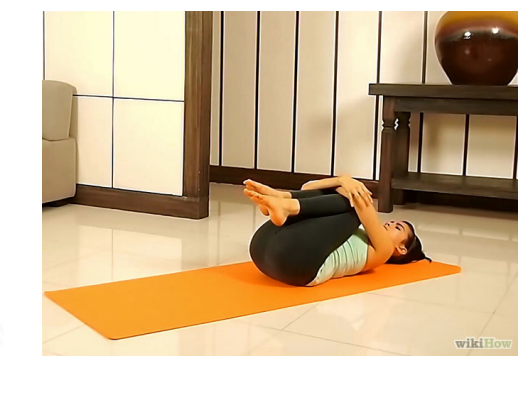

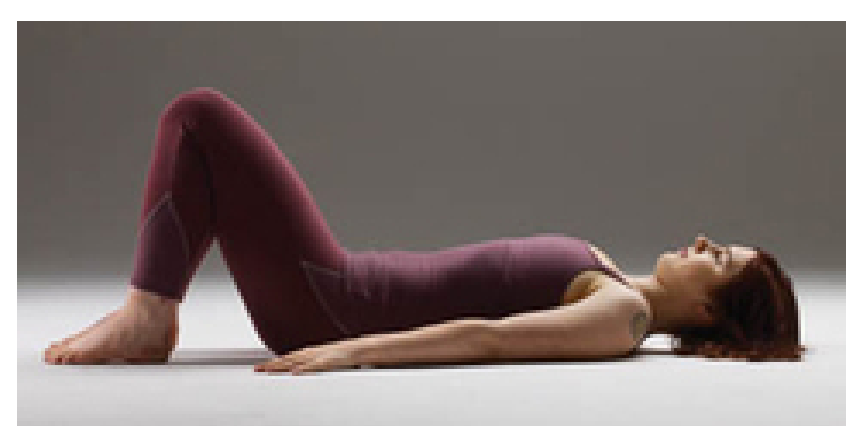

Figure 1 . The 10 poses used in the yoga mat study.

\subsection{Statistical Methods}

Student's t-tests were use to compare difference in means since all data were normally distributed.

\section{Results}

Fourteen (14) grounded subjects and fourteen (14) sham-grounded subjects participated in the one-hour study on yoga mats during which time they completed 5 twelve (12) minute sessions of ten (10) different yoga exercises. Table 2 t-test calculations show that the grounded group had a significant decrease in blood viscosity at both the systolic $(\mathrm{p}=0.032)$ and diastolic $(\mathrm{p}=0.031)$ measurements. The sham grounded subjects experienced no such 
Table 2. Grounded and sham grounded pre \& post systolic and diastolic blood viscosity in millipoise.

\begin{tabular}{|c|c|c|c|c|c|c|c|c|c|}
\hline GRND Subj & Pre Sys & Pre Dia & Post Sys & Post Dia & SHAM Subj & Pre Sys & Pre Dia & Post Sys & Post Dia \\
\hline 1 & 35.5 & 102.3 & 36.5 & 109.0 & 2 & 40.1 & 122.8 & 39.9 & 123.1 \\
\hline 3 & 40.5 & 129.0 & 38.9 & 122.3 & 5 & 43.4 & 130.2 & 39.0 & 116.5 \\
\hline 4 & 40.2 & 121.3 & 39.3 & 121.8 & 7 & 41.9 & 122.7 & 41.3 & 130.9 \\
\hline 6 & 42.0 & 128.6 & 40.8 & 124.2 & 9 & 38.1 & 109.7 & 36.8 & 103.7 \\
\hline 8 & 41.6 & 127.0 & 39.0 & 113.1 & 15 & 38.1 & 115.7 & 40.4 & 130.2 \\
\hline 14 & 43.4 & 136.9 & 41.0 & 124.9 & 16 & 34.6 & 100.3 & 36.1 & 103.6 \\
\hline 37 & 37.6 & 115.0 & 37.7 & 108.2 & 18 & 35.3 & 104.0 & 36.7 & 114.3 \\
\hline 19 & 37.6 & 113.7 & 37.7 & 115.9 & 20 & 39.4 & 120.6 & 41.5 & 127.6 \\
\hline 23 & 37.4 & 112.8 & 38.7 & 121.6 & 24 & 36.1 & 112.7 & 36.4 & 112.3 \\
\hline 25 & 35.4 & 103.2 & 35.0 & 101.5 & 26 & 37.6 & 116.0 & 38.0 & 120.3 \\
\hline 27 & 39.0 & 125.5 & 37.7 & 114.1 & 28 & 41.2 & 128.5 & 39.6 & 115.7 \\
\hline 29 & 40.8 & 129.6 & 40.9 & 129.8 & 30 & 36.5 & 112.1 & 36.3 & 111.8 \\
\hline 31 & 40.0 & 129.7 & 39.3 & 120.3 & 34 & 35.6 & 109.5 & 36.7 & 112.0 \\
\hline 32 & 37.0 & 114.8 & 36.8 & 109.9 & 36 & 35.8 & 109.0 & 37.7 & 116.9 \\
\hline Mean & 39.1 & 120.7 & 38.5 & 116.9 & Mean & 38.1 & 115.3 & 38.3 & 117.1 \\
\hline SD & 2.5 & 10.5 & 1.8 & 7.9 & SD & 2.7 & 8.8 & 1.9 & 8.6 \\
\hline \multirow[t]{2}{*}{ t-Test } & & & 0.032 & 0.031 & t-Test & & & 0.35 & 0.21 \\
\hline & & & & & t-Test g/s & 0.15 & 0.07 & 0.40 & 0.48 \\
\hline
\end{tabular}

decrease and had a slight but insignificant rise in blood viscosities. This indicates that being grounded during the yoga mat exercises has the effect of decreasing blood viscosity.

\section{Discussion}

This study examined the impact of one hour of grounding on blood viscosity while participants completed a set of simple yoga exercises. Even doing easy exercises we would expect to see an increase in blood viscosity due to the fact that exercise stimulates an inflammatory response [12] [28] [44] [45]. This response can increase the number of free radicals that could cause the red blood cells to lose some of their negative charge. The negative charge on red blood cell membranes endows the cells with the property of repelling each other. When the charge is reduced, the ability of cells to repel each other is lessened, the tendency to clump is increased, thus increasing blood viscosity [26].

While consistent exercise can induce long-term reduction in blood viscosity, in the short-term it often causes an increase in blood viscosity [44]. This increase occurs at both ends of the cardiac cycle and therefore it is important to obtain data at systole, when the viscosity is lower, and at diastole, when the viscosity is higher. Collecting at only one point is equivalent to collecting only systolic or diastolic blood pressure or measuring blood pressure at some point in between. At the systolic pressure, information with respect to the condition of the walls of the vessels is obtained. At the diastolic end, information with respect to red cell aggregation and deformability is obtained.

In our study there was no change in blood viscosity for the sham-grounded group at either end of the cardiac cycle. However, there was a difference in the grounded group at both the systolic and diastolic end. Their post onehour grounding millipoise readings were significantly lower than their pre-exercise levels.

Considering all aforementioned dynamics, and with electrons from grounding theoretically scavenging free radicals, it may logically be concluded that inflammation, as a result of exercise, could have been reduced and 
this effect, in turn, reduced the blood viscosity in the grounded subjects.

Limitations of this pilot study were the number of subjects and methods of measurement of blood viscosity. Future research projects should include more subjects as well as adding zeta potential measurements, another indicator of blood viscosity [26].

\section{Conclusion}

Blood viscosity may be an early predictor of chronic disease. Since equipment is now available to reliably measure this parameter, more investigations should be undertaken. Habits, as well as certain medications, can lower blood viscosity. But medications are often expensive and present unwanted side effects. A potential treatment that presents no downside is grounding the body to the earth. In this study it was shown that, despite mild exercise that can raise blood viscosity temporarily, blood viscosity was lowered at both the systolic and diastolic ends of the cardiac cycle in subjects using grounded yoga mats. Earthing has the ability to affect exercise-induced inflammation by reducing blood viscosity.

\section{Acknowledgements}

The authors wish to acknowledge the professional assistance of Legacy Laboratories in Eugene, OR, and Health Onvector, Inc. of Camden, NJ. Also, the authors wish to thank Martin Zucker and James L. Oschman for reviewing the manuscript and for making useful suggestions. Earthing products were provided by earthing.com, Palm Spring, CA. Financial support for this project was provided by Earth FX Inc., Palm Springs, CA.

\section{Declaration of Interest}

R. Brown worked as an independent contractor for this pilot study and has no financial interest in the company. G. Chevalier has worked as an independent contractor for Earth FX since 2007 and owns a very small percentage of shares in the company.

\section{References}

[1] Williams, E.R. and Heckman, S.J. (1993) The Local Diurnal Variation of Cloud Electrification and the Global Diurnal Variation of Negative Charge on the Earth. Journal of Geophysical Research, 98, 5221-5234. http://dx.doi.org/10.1029/92JD02642

[2] Anisimov, S.V., Mareev, E.A. and Bakastov, S.S. (1999) On the Generation and Evolution of Aeroelectric Structures in the Surface Layer. Journal of Geophysical Research, 104, 14359-14367. http://dx.doi.org/10.1029/1999JD900117

[3] Applewhite, R. (2005) The Effectiveness of a Conductive Patch and a Conductive Bed Pad in Reducing Induced Human Body Voltage via the Application of Earth Ground. European Biology and Bioelectromagnetics, 1, 23-40. http://www.earthingoz.com.au/pdf/Applewhite earthing body voltage 2005.pdf

[4] Oschman, J.L. (2009) Charge Transfer in the Living Matrix. Journal of Bodywork and Movement Therapies, 13, 215228. http://dx.doi.org/10.1016/j.jbmt.2008.06.005

[5] Oschman, J.L. (2007) Can Electrons Act as Antioxidants? A Review and Commentary. Journal of Alternative and Complementary Medicine, 13, 955-967. http://online.liebertpub.com/doi/pdfplus/10.1089/acm.2007.7048 http://dx.doi.org/10.1089/acm.2007.7048

[6] Chevalier, G., Sinatra, S.T., Oschman, J.L., Sokal, K. and Sokal, P. (2012) Earthing: Health Implications of Reconnecting the Human Body to the Earth's Surface Electrons. Journal of Environmental and Public Health, 2012, Article ID: 291541. http://dx.doi.org/10.1155/2012/291541

[7] Brown, R., Chevalier, G. and Hill, M. (2010) Pilot Study on the Effect of Grounding on Delayed-Onset Muscle Soreness. Journal of Alternative and Complementary Medicine, 16, 265-273. http://dx.doi.org/10.1089/acm.2009.0399

[8] Brown, R., Chevalier, G. and Hill, M. (2015) Grounding after Moderate Eccentric Contractions Reduces Muscle Damage. International Blood Research \& Review, Unpublished.

[9] Oschman, J., Chevalier, G. and Brown, R. (2015) The Effects of Grounding (Earthing) on Inflammation, the Immune Response, Wound Healing, and Prevention and Treatment of Chronic Inflammatory and Autoimmune Diseases. Journal of Inflammation Research, 8, 83-96. http://dx.doi.org/10.2147/JIR.S69656

[10] Oschman, J., Chevalier, G. and Ober, A. (2015) Biophysics of Earthing (Grounding) the Human Body. In: Rosch, P.J., Ed., Bioelectromagnetic and Subtle Energy Medicine, 2nd Edition, CRC Press, New York, 427-448.

[11] Curtis, D., Fallows, S., Morris, M. and McMakin, C. (2010) The Efficacy of Frequency Specific Microcurrent Therapy 
on Delayed Onset Muscle Soreness. Journal of Bodywork and Movement Therapies, 14, 272-279. http://dx.doi.org/10.1016/j.jbmt.2010.01.009

[12] Brun, J.F. (2002) Exercise Hemorheology as a Three Acts Play with Metabolic Actors: Is It of Clinical Relevance? Clinical Hemorheology and Microcirculation, 26, 155-174.

[13] Brun, J.F., Belhabas, H., Granat, M.Ch., Sagnes, C., Thöni, G., Micallef, J.P. and Mercier, J. (2002) Postexercise Red Cell Aggregation Is Negatively Correlated with Blood Lactate Rate of Disappearance. Clinical Hemorheology and Microcirculation, 26, 231-239.

[14] Fernandes, H.P., Cesar, C.L. and Barjas-Castro Mde, L. (2011) Electrical Properties of the Red Blood Cell Membrane and Immunohematological Investigation. Revista Brasileira de Hematologia e Hemoterapia, 33, 297-301. http://dx.doi.org/10.5581/1516-8484.20110080

[15] Pop, G.A., Duncker, D.J., Gardien, M., Vranckx, P., Versluis, S., Hasan, D. and Slager, C.J. (2002) The Clinical Significance of Whole Blood Viscosity in (Cardio) Vascular Medicine. Netherlands Heart Journal: Monthly Journal of the Netherlands Society of Cardiology and the Netherlands Heart Foundation, 10, 512-516.

[16] Larsen, P. (2012) Monitoring Blood Viscosity to Improve Cognitive Function. Washington Association of Naturopathic Physicians, Fall Issue 2012.

[17] Rosenson, R.S., Fioretto, P. and Dodson, P.M. (2011) Does Microvascular Disease Predict Macrovascular Events in Type 2 Diabetes? Atherosclerosis, 218, 13-18. http://dx.doi.org/10.1016/j.atherosclerosis.2011.06.029

[18] Jeong, S.K., Cho, Y.I., Duey, M. and Rosenson, R.S. (2010) Cardiovascular Risks of Anemia Correction with Erythrocyte Stimulating Agents: Should Blood Viscosity Be Monitored for Risk Assessment? Cardiovascular Drugs and Therapy/Sponsored by the International Society of Cardiovascular Pharmacotherapy, 24, 151-160.

[19] Cho, Y.I. and Cho, D.J. (2011) Hemorheology and Microvascular Disorders. Korean Circulation Journal, 41, $287-295$. http://dx.doi.org/10.4070/kcj.2011.41.6.287

[20] Fernandes, H.P., Fontes, A., Thomaz, A., Castro, V., Cesar, C.L. and Barjas-Castro, M.L. (2013) Measuring Red Blood Cell Aggregation Forces Using Double Optical Tweezers. Scandinavian Journal of Clinical \& Laboratory Investigation, 73, 262-264. http://dx.doi.org/10.3109/00365513.2013.765961

[21] Baskurt, O.K., Uyuklu, M., Ozdem, S. and Meiselman, H.J. (2011) Measurement of Red Blood Cell Aggregation in Disposable Capillary Tubes. Clinical Hemorheology and Microcirculation, 47, 295-305.

[22] Simmonds, M.J., Rhys, C., Marshall-Gradisnik, S.M., Meiselman, H.J. and Baskurt, O.K. (2011) Red Blood Cell Aggregation Parameters Measured by Capillary Tube Aggregometer Using Venous and Capillary Blood Samples. Korea-Australia Rheology Journal, 23, 205-210. http://dx.doi.org/10.1007/s13367-011-0025-3

[23] Baskurt, O.K. and Meiselman, H.J. (1997) Cellular Determinants of Low-Shear Blood Viscosity. Biorheology, 34, 235-247. http://dx.doi.org/10.1016/S0006-355X(97)00027-9

[24] Tripette, J., Alexy, T., Hardy-Dessources, M.D., Mougenel, D., Beltan, E., Chalabi, T., Chout, R., Etienne-Julan, M., Hue, O., Meiselman, H.J. and Connes, P. (2009) Red Blood Cell Aggregation, Aggregate Strength and Oxygen Transport Potential of Blood Are Abnormal in both Homozygous Sickle Cell Anemia and Sickle-Hemoglobin C Disease. Haematologica, 94, 1060-1065. http://dx.doi.org/10.3324/haematol.2008.005371

[25] Brun, J.F., Varlet-Marie, E., Romain, A.J., Guiraudou, M. and Raynaud de Mauverger, E. (2013) Exercise Hemorheology: Moving from Old Simplistic Paradigms to a More Complex Picture. Clinical Hemorheology and Microcirculation, 55, 15-27.

[26] Chevalier, G., Sinatra, S.T., Oschman, J.L. and Delany, R.M. (2013) Earthing (Grounding) the Human Body Reduces Blood Viscosity-A Major Factor in Cardiovascular Disease. Journal of Alternative and Complementary Medicine, 19, 102-110. http://dx.doi.org/10.1089/acm.2011.0820

[27] Lowe, G., Rumley, A., Norrie, J., Ford, I., Shepherd, J., Cobbe, S., Macfarlane, P. and Packard, C. (2000) Blood Rheology, Cardiovascular Risk Factors, and Cardiovascular Disease: The West of Scotland Coronary Prevention Study. Thrombosis and Haemostasis, 84, 553-558.

[28] Sloczyńska, K., Kózka, M. and Marona, H. (2013) Red Blood Cell Deformability and Aggregation in Chronic Venous Disease Patients with Varicose Veins. Postęy Higieny i Medycyny Doświadczalnej, 67, 690-694. http://www.phmd.pl/fulltxt.php?ICID=1059670 http://dx.doi.org/10.5604/17322693.1059670

[29] Stein, P.D. and Sabbah, H.N. (1974) Measured Turbulence and Its Effect on Thrombus Formation. Circulation Research, 35, 608-614. http://dx.doi.org/10.1161/01.RES.35.4.608

[30] Traub, O. and Berk, B.C. (1998) Laminar Shear Stress: Mechanisms by Which Endothelial Cells Transduce an Atheroprotective Force. Arteriosclerosis, Thrombosis, and Vascular Biology, 18, 677-685. http://dx.doi.org/10.1161/01.ATV.18.5.677

[31] Holsworth, R.E. and Wright, J.V. (2012) Blood Viscosity: The Unifying Parameter in Cardiovascular Disease Risk. 
Holistic Primary Care, 13, 1-2.

https://holisticeducationexchange.net/topics/cardiovascular-health/996-blood-viscosity-the-unifying-parameter-in-cardi ovascular-disease-risk.html

[32] Cassilhas, R.C., Viana, V.A.R., Grassmann, V., Santos, R.T., Santos, R.F., Tufik, S. and Mello, M.T. (2007) The Impact of Resistance Exercise on the Cognitive Function of the Elderly. Medicine \& Science in Sports \& Exercise, 39, 1401-1407. http://dx.doi.org/10.1249/mss.0b013e318060111f

[33] Lowe, G.D., Lee, A.J., Rumley, A., Price, J.F. and Fowkes, F.G. (1997) Blood Viscosity and Risk of Cardiovascular Events: The Edinburgh Artery Study. British Journal of Haematology, 96, 168-173. http://dx.doi.org/10.1046/j.1365-2141.1997.8532481.X

[34] Ciuffetti, G., Schillaci, G., Lombardini, R., Pirro, M., Vaudo, G. and Mannarin, E. (2005) Prognostic Impact of LowShear Whole Blood Viscosity in Hypertensive Men. European Journal of Clinical Investigation, 35, 93-98. http://dx.doi.org/10.1111/j.1365-2362.2005.01437.x

[35] Letcher, R.L., Chien, S., Pickering, T.G., Sealey, J.E. and Laragh, J.H. (1981) Direct Relationship between Blood Pressure and Blood Viscosity in Normal and Hypertensive Subjects: Role of Fibrinogen and Concentration. The American Journal of Medicine, 70, 1195-1202. http://dx.doi.org/10.1016/0002-9343(81)90827-5

[36] Jeong, S.K. and Rosensen, R. (2013) Shear Rate Specific Blood Viscosity and Shear Stress of Carotid Artery Duplex Ultrasonography in Patients with Lacunar Infarction. BMC Neurology, 13, 36. http://dx.doi.org/10.1186/1471-2377-13-36

[37] Larsen, P. and Holsworth, R. (2012) Measuring Blood Viscosity to Improve Patient Outcomes. Townsend Letter: The Examiner of Alternative Medicine. http://www.townsendletter.com/Jan2012/measureblood0112.html

[38] Cho, Y.I. and Kensey, K.R. (1991) Effects of the Non-Newtonian Viscosity of Blood on Flows in a Diseased Arterial Vessel. Part 1: Steady Flows. Biorheology, 28, 241-262.

[39] Marton, Z., Kesmarky, G., Vekasi, J., Cser, A., Russai, R., Horvath, B. and Toth, K. (2001) Red Blood Cell Aggregation Measurements in Whole Blood and in Fibrinogen Solutions by Different Methods. Clinical Hemorheology and Microcirculation, 24, 75-83.

[40] Hemathix Blood Analyzer (2013) Blood Viscosity Test Specimen Requirements. Rheovector LLC, Camden, 1.

[41] Woodcock, B.E., Smith, E., Lambert, W.H., Jones, W.M., Galloway, J.H., Greaves, M. and Preston, F.E. (1984) Beneficial Effect of Fish Oil on Blood Viscosity in Peripheral Vascular Disease. British Medical Journal (Clinical Research Ed.), 288, 592-594. http://dx.doi.org/10.1136/bmj.288.6417.592

[42] Sinatra, S.T. (2003) Is Cholesterol Lowering with Statins the Gold Standard for Treating Patients with Cardiovascular Risk and Disease? Southern Medical Journal, 96, 220-222. http://dx.doi.org/10.1097/01.SMJ.0000051743.83926.12

[43] Carroll, S., Cooke, C.B. and Butterly, R.J. (2000) Physical Activity, Cardiorespiratory Fitness, and the Primary Components of Blood Viscosity. Medicine and Science in Sports and Exercise, 32, 353-358. http://dx.doi.org/10.1097/00005768-200002000-00014

[44] El-Sayed, M. (1998) Effects of Exercise and Training on Blood Rheology. Sports Medicine (Auckland, N.Z.), 26, 281292. http://dx.doi.org/10.2165/00007256-199826050-00001

[45] Ernst, E.E. and Matrai, A. (1987) Intermittent Claudication, Exercise, and Blood Rheology. Circulation, 76, $1110-1114$. http://dx.doi.org/10.1161/01.CIR.76.5.1110

[46] Brun, J.F., Khaled, S., Raynaud, E., Bouix, D., Micallef, J.P. and Orsetti, A. (1998) The Triphasic Effects of Exercise on Blood Rheology: Which Relevance to Physiology and Pathophysiology? Clinical Hemorheology and Microcirculation, 19, 89-104. 